University of New Hampshire

University of New Hampshire Scholars' Repository

Jackson Estuarine Laboratory

Institute for the Study of Earth, Oceans, and

Space (EOS)

8-1-2013

\title{
Patterns of Activity Expressed by Juvenile Horseshoe Crabs
}

Winsor H. Watson III

University of New Hampshire, Durham, win.watson@unh.edu

Elizabeth A. Dubofsky

University of New Hampshire, Durham

S. D. Simpson

University of New Hampshire, Durham

Christopher C. Chabot

Plymouth State University

Follow this and additional works at: https://scholars.unh.edu/jel

\section{Recommended Citation}

Dubofsky, E. A., S. D. Simpson, C. C. Chabot and W. H. Watson III. 2013. Patterns of Activity Expressed by Juvenile Horseshoe Crabs. Biol. Bull. 225: 42-49. https://doi.org/10.1086/BBLv225n1p42

This Article is brought to you for free and open access by the Institute for the Study of Earth, Oceans, and Space (EOS) at University of New Hampshire Scholars' Repository. It has been accepted for inclusion in Jackson Estuarine Laboratory by an authorized administrator of University of New Hampshire Scholars' Repository. For more information, please contact Scholarly.Communication@unh.edu. 


\title{
Patterns of Activity Expressed by Juvenile Horseshoe Crabs
}

\author{
E. A. DUBOFSKY ${ }^{1}$, S. D. SIMPSON ${ }^{2}$, CHRISTOPHER C. CHABOT $^{2}$, AND \\ WINSOR H. WATSON III ${ }^{1 *}$ \\ ${ }^{1}$ Department of Biological Sciences, University of New Hampshire, Durham, New Hampshire 03824; \\ and ${ }^{2}$ Department of Biological Sciences, Plymouth State University, Plymouth, New Hampshire 03264
}

\begin{abstract}
Adult American horseshoe crabs, Limulus polyphemus, possess endogenous circadian and circatidal clocks controlling visual sensitivity and locomotion, respectively. The goal of this study was to determine the types of activity rhythms expressed by juvenile horseshoe crabs $(n=$ 24) when exposed to a 14:10 light/dark cycle (LD) for 10 days, followed by 10 days of constant darkness (DD). Horseshoe crab activity was recorded with a digital timelapse video system that used an infrared-sensitive camera so animals could be monitored at night. In LD, 15 animals expressed daily patterns of activity, 6 displayed a circatidal pattern, and the remaining 3 were arrhythmic. Of the 15 animals with daily patterns of locomotion, 7 had a significant preference $(P<0.05)$ for diurnal activity and 3 for nocturnal activity; the remainder did not express a significant preference for day or night activity. In DD, 13 horseshoe crabs expressed circatidal rhythms and 8 maintained a pattern of about $24 \mathrm{~h}$. Although these results suggest the presence of a circadian clock influencing circatidal patterns of locomotion, these apparent circadian rhythms may actually represent the expression of just one of the two bouts of activity driven by the putative circalunidian clocks that control their tidal rhythms. Overall, these results indicate that, like adults, juvenile horseshoe crabs express both daily and tidal patterns of activity and that at least one, and maybe both, of these patterns is driven by endogenous clocks.
\end{abstract}

\section{Introduction}

Animals inhabiting, or visiting, the intertidal zone often express either a daily pattern of activity (synchronized to the

Received 2 January 2013; accepted 13 May 2013.

* To whom correspondence should be addressed. E-mail: win@unh.edu Abbreviations: LD, light/dark; DD, constant darkness. light cycle), a tidal pattern (synchronized to the tidal cycle), or some combination of the two. Three intertidal organisms whose activity patterns have been scrutinized in detail are the green crab (Carcinus maenas, Naylor, 1958), mole crab (Emerita talpoida, Forward et al., 2005), and fiddler crab (Uca spp., Bennett et al., 1957; Barnwell, 1966). All three exhibit a combination of tidal and daily patterns of activity, and within each species, there is wide individual variation in the patterns expressed. This variation has been attributed to varying selection pressures, native environments, reproductive status, and molt states (Bennett et al., 1957; Naylor, 1958; Barnwell, 1966; Forward et al., 2005). Importantly, when these three species are placed in the laboratory under constant conditions, the rhythms persist, indicating that they are driven by endogenous biological clocks (Bennett et al., 1957; Naylor, 1958; Aschoff, 1960; Barnwell, 1966; Forward et al., 2005).

Another common species that inhabits or visits the intertidal zone is the American horseshoe crab, Limulus polyphemus (Linnaeus). Adult horseshoe crabs are known to express both tidal and daily rhythms of locomotion (Chabot et al., 2011). They also have an endogenous circadian rhythm of visual sensitivity, enabling their eyes to become approximately 1,000,000 times more sensitive to light at night (Barlow et al., 1980; Barlow, 1983; Barlow and Powers, 2003). However, at least in adults, it appears that the circadian clock controlling eye sensitivity does not control patterns of locomotion (Watson et al., 2008). To date, in adult horseshoe crabs, only their tidal pattern of activity has been clearly demonstrated to be under the control of an endogenous clock (Chabot et al., 2004, 2007, 2008, 2011; Watson et al., 2008, 2009; Chabot and Watson, 2010; Watson and Chabot, 2010). At present, there are no data demonstrating a circadian clock controlling locomo- 
tion, even though many adult horseshoe crabs exposed to an LD cycle express a preference for either daytime or nighttime activity (Chabot et al., 2004, 2007, 2011). Thus, like the three aforementioned crabs, some horseshoe crabs display a complex pattern of activity that is a mixture of daily and tidal components.

Larval horseshoe crabs also express both tidal and daily activity rhythms. After they hatch from their egg cases, larvae spend up to 6 days in the water column before they settle to the bottom; during this time they are positively phototactic and most active at night and during high tides (Rudloe, 1979; Shuster, 1982). When collected in the field and brought into the laboratory, larvae express a circatidal rhythm of activity in constant conditions, becoming active near the start of the expected ebb tide (Ehlinger and Tankersley, 2006). Moreover, they can be entrained to 12.4-h cycles of agitation and will continue to show a circatidal rhythm of activity when the agitation cycles are terminated (Ehlinger and Tankersley, 2006). Therefore, like adult horseshoe crabs, larvae clearly have a circatidal clock that controls the timing of their activity, and while they also appear to have a preference for nocturnal activity and can sense light (Errigo et al., 2001; Meadors et al., 2001), there is no evidence for an underlying circadian clock influencing their activity.

Juvenile horseshoe crabs also appear to be influenced by tidal cycles and daily changes in light levels. A simulated ebbing tide causes animals to follow the water down the beach and bury in the sand at the edge of the water. They move only when covered with water, and they express a preference for slack tide (Meury and Gibson, 1990). Studies of juveniles of the horseshoe crab species Tachypleus tridentatus in Japan revealed that they increased their activity $2 \mathrm{~h}$ before low tide; however, no data were collected during high tides (Chiu and Morton, 2004). Juvenile horseshoe crabs in Florida also express a peak of activity $2 \mathrm{~h}$ prior to low tide, during the ebb tide. However, when they are placed in subtidal enclosures in water deeper than where they are typically found, activity correlates to the light rather than the tidal cycle (Rudloe, 1981). In a laboratory study by Rudloe (1981), juvenile horseshoe crabs exposed to water of a constant depth, ambient light, and ambient temperature expressed diurnal activity. However, because the animals were not exposed to constant light conditions and some equipment malfunctions limited the amount of data obtained, it was not possible to determine if their daily rhythms were driven by an endogenous circadian clock.

Two other laboratory studies determined that juvenile American horseshoe crabs tended to be nocturnal, but due to the low sample size and short duration of the studies, firm conclusions could not be drawn about the factors giving rise to this pattern of activity (Casterlin and Reynolds, 1979; Borst and Barlow, 2002). Further, the length of time and conditions under which they were held prior to testing were not described in these papers. This is important because tidal rhythms tend to degrade in the laboratory (Palmer, 1995b; Chabot et al., 2008), which might explain why these animals were mainly nocturnal. The study by Borst and Barlow (2002) tested for endogenous rhythms, but the resolution of the data (by hour) was not fine enough to determine whether the patterns expressed were circatidal or circadian. Therefore, while the main conclusion of the study was that juvenile horseshoe crabs are nocturnal, there were also indications that the horseshoe crabs might have expressed circatidal or circadian patterns of locomotion, or a combination of the two.

The primary goal of our study was to determine the types of activity rhythms expressed by juvenile horseshoe crabs when exposed to a summer LD cycle and then placed in DD. In the first situation, the data obtained permitted us to test the hypothesis that these animals have an endogenous clock that enables them to express a tidal rhythm of activity in the absence of any tidal cues. The constant darkness section of the experiment was designed to test the hypothesis that juvenile horseshoe crabs have an endogenous circadian clock that enables them to express a roughly $24-\mathrm{h}$ rhythm in the absence of LD cues. Finally, the combination of the two phases of the experiment made it possible to determine if LD input might override an underlying tendency of some animals to express a tidal rhythm of activity.

In LD conditions, we found that most animals expressed a daily rhythm of activity, and the majority of those preferred to be most active during the daytime. Eight of the 15 animals that expressed a daily rhythm in LD continued this pattern in DD. A number of animals expressed a tidal rhythm of activity both in LD and DD, clearly indicating the presence of a circatidal clock influencing their tendency to be active. However, more animals expressed tidal rhythms in DD than in LD, suggesting that LD cycles may, at least partially, override their expression of endogenous tidal rhythms. These data, taken together, also suggest that the complex patterns of behavior expressed by juvenile horseshoe crabs, and perhaps some of the aforementioned marine invertebrates, are likely the result of the interactions between at least one endogenous clock and natural LD cycles.

\section{Materials and Methods}

\section{Collection and care of animals}

Juveniles of Limulus polyphemus, 40-55 mm in carapace width ( 3-4 years in age, Sekiguchi et al., 1988), were collected from Little Sippewissett Marsh, Falmouth, Massachusetts, on four dates in 2010 (9 June, 2 July, 22 August, and 1 September). This area experiences a semidiurnal tidal pattern, with two high and two low tides of about equal size within each lunar day.

After collection, animals were transported in coolers to an indoor facility at the University of New Hampshire, Dur- 
ham, New Hampshire. Less than 24 h elapsed between collection, placement of animals in individual chambers, and initiation of recordings. The activity patterns expressed by 24 juveniles were recorded during four trials, each lasting 20 days. In the trials that began on 9 June and 2 July 2010, five animals were used, and in the trials beginning on 22 August and 1 September 2010, seven animals were used.

Prior to the start of a trial, all animals were fed to satiation using frozen Spirulina brine shrimp (Hikari Bio-Pure, Hikari, Hayward, CA) thawed in saltwater. Satiation was determined by cessation of food consumption, based on the end of the stereotyped feeding movements of the legs, as described by Wyse and Dwyer (1973).

\section{Monitoring animal activity}

To increase the visibility of animals at night, cyanoacrylate-based glue was used to attach a $1-\mathrm{cm}^{2}$ piece of reflective tape to the dorsal carapace of each horseshoe crab. The tape did not cover any of the simple or complex eyes. Horseshoe crabs were then placed in individual $20-\mathrm{cm}-$ diameter plastic chambers filled with $3 \mathrm{~cm}$ of sand and 15 $\mathrm{cm}$ of 30 psu seawater held in an air-conditioned room that was slightly cooler than normal room temperature (range 18.6-21.9 ${ }^{\circ} \mathrm{C}$ ). For the first 10 days of the experiment, animals were subjected to a summer LD cycle (14:10) using a modified dawn/dusk simulator to gradually increase and decrease incandescent lights for $2 \mathrm{~h}$ at the beginning and end of each day (SunUp, Light Therapy Products, Plymouth, MA). Imposed laboratory light cycles were within $\pm 1 \mathrm{~h}$ of the ambient light cycle at the time of collection. Light levels were $163 \pm 0.35$ lux (mean \pm S.E.M., $n=$ $24,190)$ during the day and $<10$ lux at night. Light levels were measured using a HOBO Pendant Temperature/Light data logger (Onset Computer Corporation, Bourne, MA), which took one reading per minute. All samples from the time sunrise was initiated to the end of sunset were averaged to calculate the daytime light levels, and light samples from the end of sunset until the start of sunrise were averaged to calculate the nighttime light levels. At the end of the initial 10-day period, animals were subjected to 10 days of constant darkness (DD). During DD, and the nights associated with LD, infrared lights illuminated the chambers. Infrared lights were chosen for illumination due to the limited ability of horseshoe crabs to see in this part of the spectrum (Graham and Hartline, 1935; Chapman and Lall, 1967; reviewed in Battelle, 2006).

Activity was recorded using black-and-white, infraredsensitive cameras (PC-222, Supercircuits, Austin, TX). Camera outputs were digitized (Canopus ADVC-110, Grass Valley, San Francisco, CA), time-stamped, and recorded with a computer (Macintosh, OS 10.5.6) using video capture software (Gawker, ver. 0.8.3, Seattle, WA) that captured one frame every $30 \mathrm{~s}$. In trials 1 and 2, a single camera was used to simultaneously record the activity of the animals in all of the chambers. In trials 3 and 4, a multiplexer (Pelco Genex MX4009MD, 9 channel) was used to combine the output of four cameras into a single video stream that was digitized as previously described.

Videos were analyzed by eye in 5-min blocks. Any movement during a block was recorded as 1 ; no movement was recorded as 0 . These data were then plotted and analyzed further as actograms and Lomb-Scargle periodograms $(P<$ 0.001), using the program ClockLab (MatLab, Actimetrics, Evanston, IL, ver. R2009a), as described in Chabot et al. (2008). The maximum Lomb-Scargle periodogram peak in the circadian (periods of 22-26 h) or circatidal (periods of 10.4-14.4 h) range was used to determine if animals expressed circadian $(\sim 24 \mathrm{~h})$ or circatidal $(\sim 12.4 \mathrm{~h})$ activity patterns. Actograms were also visually inspected to confirm the results yielded by the periodogram analyses, with specific attention paid to the number of activity bouts each day. Significant differences in activity levels during the day and night were determined for animals that expressed a daily rhythm in LD. The percentage of each hour that animals were active during light hours and dark hours was calculated by calendar day and compared using a nonparametric Wilcoxon matched-pairs signed-ranks test using InStat (GraphPad Software, La Jolla, CA, ver. 3.1a 2009). To determine alpha, or the duration of the main bout of activity, best eye-fit lines were drawn, using a single-blind protocol, through the "onset" and "offset" of active periods.

\section{Results}

Of the 24 animals tested, 15 (63\%) expressed a daily rhythm of activity when exposed to the light/dark cycle $(\mathrm{LD})(\operatorname{tau}(\tau)=23.90 \pm 0.35 \mathrm{~h}$; mean \pm S.E.M.; $P<$ 0.001 ; Figs. 1, 2, 3). Six of the original 24 animals $(25 \%)$ expressed primarily circatidal rhythms of activity during LD $(\tau=12.36 \pm 0.20$ h, Fig. 4$)$. There was no clear correlation between the circatidal rhythms seen in the laboratory and the natural tidal cycle of the collection location. Three of the 24 animals tested did not show a clear pattern of activity (arrhythmic).

Of the 15 animals expressing daily rhythms in LD, 7 (47\%) were significantly more active during the day and 3 (20\%) during the night (Wilcoxon matched-pairs signedranks test, diurnal: $54<\mathrm{W}<110, P<0.0302$; nocturnal: $-52<\mathrm{W}<-78, P<0.02)$. The remaining five animals did not express significantly different activity levels between day and night. When animals that were diurnal during LD were exposed to constant darkness (DD), 3 expressed a circadian rhythm of activity, while 4 switched to a circatidal pattern of activity. Of the 3 animals that were most active at night in LD, one maintained an activity rhythm of about $24 \mathrm{~h}$ in DD, while 2 switched to circatidal patterns of behavior. 


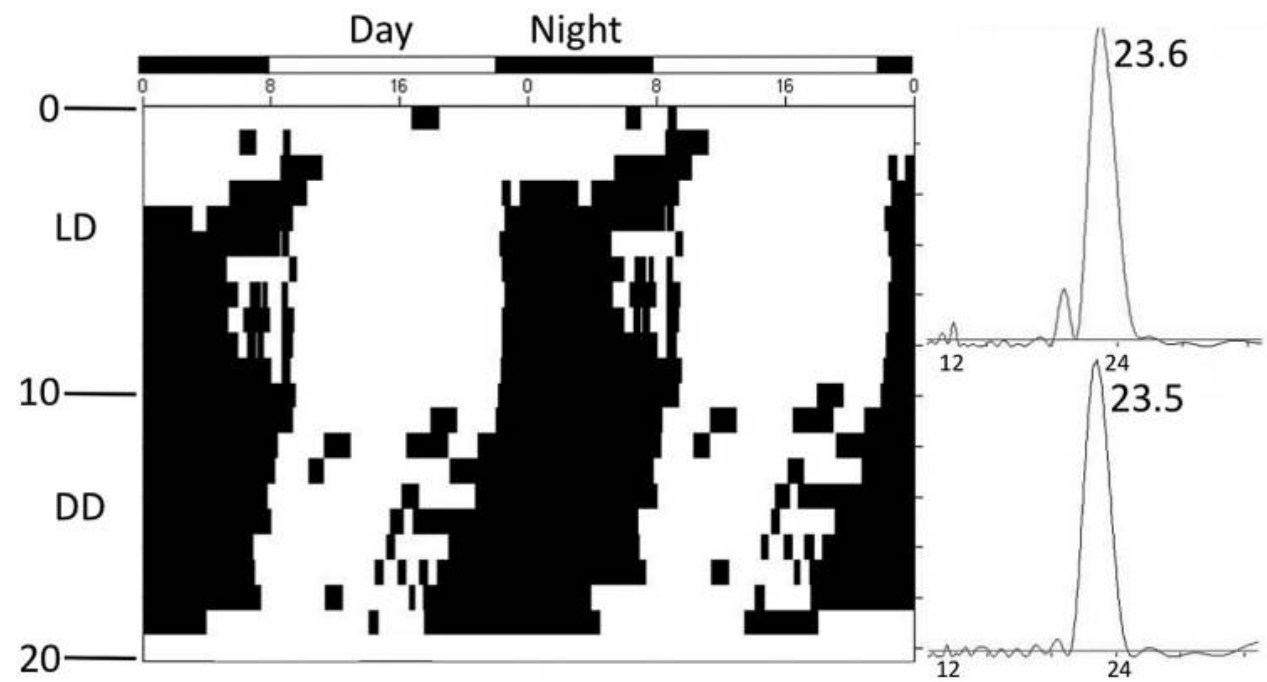

Figure 1. Locomotor activity of a juvenile horseshoe crab expressing a daily pattern of activity during an imposed light/dark cycle (LD), and a circadian pattern in constant darkness (DD). Image on the left is a double-plotted actogram; activity is indicated by black tick marks. LD is indicated at the top of the image. During the first 10 days, horseshoe crabs were exposed to a 14:10 LD cycle, and during the second 10 days they were in DD. Images on the right are Lomb-Scargle periodograms for the same animal during either the LD period (top) or the DD period (bottom). Vertical scale is the relative strength of rhythmicity $(\mathrm{Q}(\mathrm{p}))$; the horizontal axis shows the length of periods in hours $(10-30)$; the largest peak above the horizontal line of significance $(P<0.001)$ is indicated by a numerical value.

When exposed to DD, 7 of the 15 animals that expressed a daily rhythm in LD continued to express a rhythm of activity of about $24 \mathrm{~h}(\tau=23.38 \pm 0.30 \mathrm{~h}$; Fig. 1$)$, while 8 switched to circatidal rhythms of activity $(\tau=15.02 \pm$ 1.83 h; Figs. 2, 3). Five of the 6 animals that originally expressed a circatidal rhythm in LD continued this same pattern of behavior when subjected to DD $(\tau=12.48 \pm$ $0.13 \mathrm{~h}$, Fig. 4). One animal switched from a circatidal pattern of behavior in LD to an activity rhythm of about $24 \mathrm{~h}$ in DD $(\tau=23.45$, data not shown). Thus, in DD, $13 / 24$ exhibited circatidal rhythms, while 8/24 exhibited apparent circadian rhythms ( $\sim 24 \mathrm{~h}$ rhythm of activity) with one

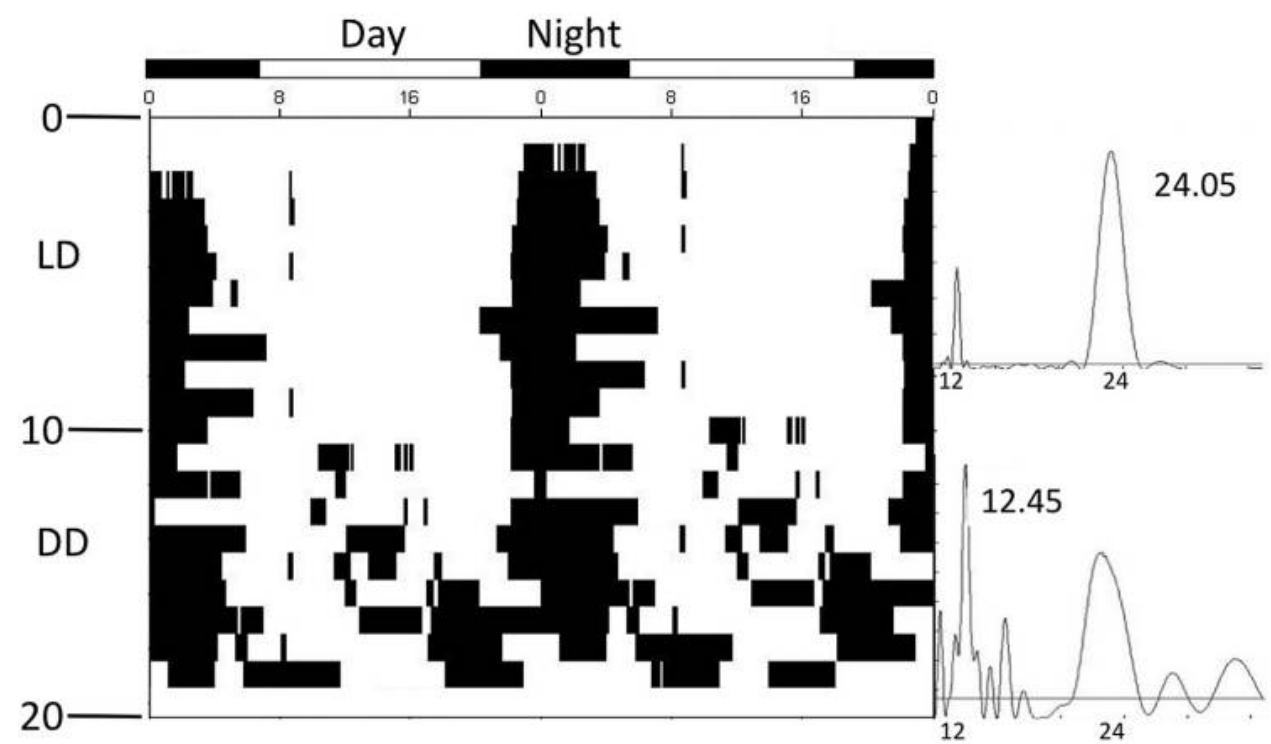

Figure 2. Locomotor activity of a horseshoe crab expressing a nocturnal pattern of activity in LD and a circatidal rhythm in DD. See Fig. 1 for a detailed description of figure components. 


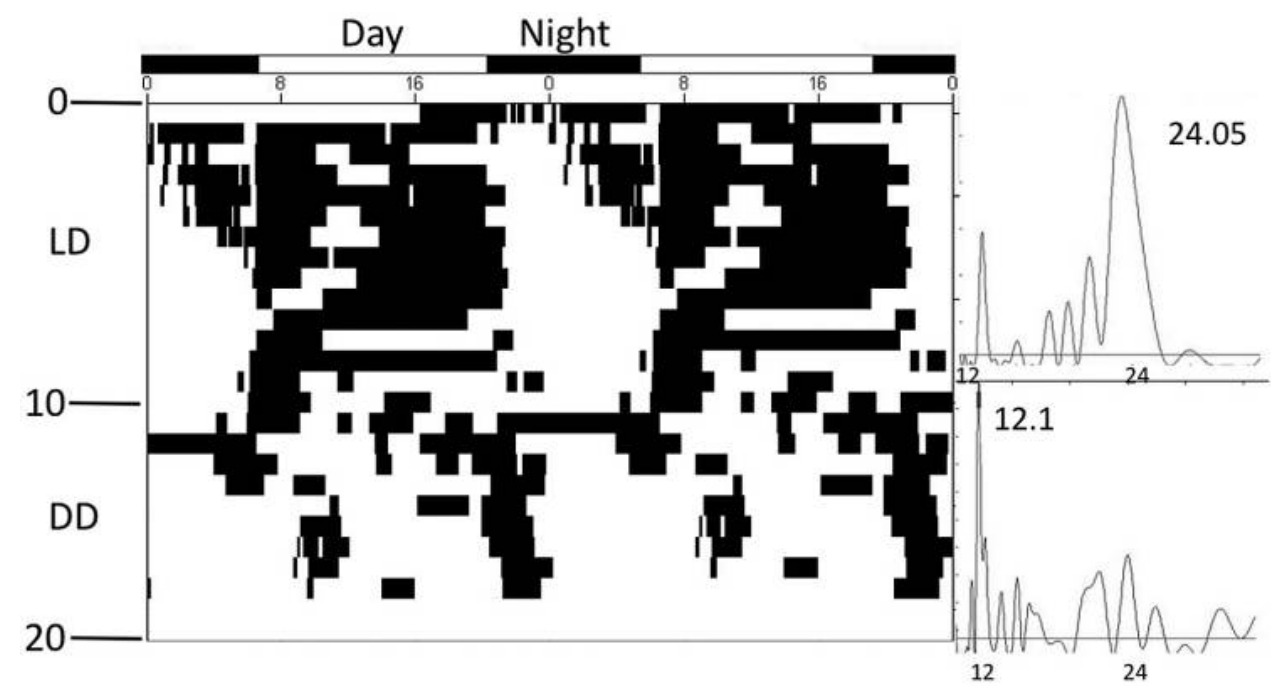

Figure 3. The locomotor activity of a juvenile horseshoe crab that expressed one diurnal bout of activity per day during LD that split into two bouts of activity per day, or a circatidal rhythm, in DD. See Fig. 1 for a full description of figure components.

peak of activity per $24 \mathrm{~h}$. However, it should be noted that several of the animals that exhibited a unimodal, apparently circadian, pattern of activity also expressed secondary peaks of activity in the circatidal range $(\tau=12.01 \pm 0.24 \mathrm{~h}$, data not shown). There was no clear correlation between the circatidal rhythms expressed under DD conditions in the laboratory and the natural tidal cycle of the collection location.

Activity duration (alpha) was calculated for 11 animals (the remaining animals did not have clear enough patterns to calculate alpha). During the LD portion of the experiment, nocturnal animals had bouts of activity lasting $9.32 \pm$ $2.20 \mathrm{~h}(n=6$, D lasted $10 \mathrm{~h}$ in the 14:10 LD cycle). The one clear diurnal animal had an alpha of $16.4 \mathrm{~h}$ (L lasted $14 \mathrm{~h}$ ), and the four circatidal animals expressed bouts of activity that were $7.39 \pm 1.66 \mathrm{~h}$ long. During DD, alpha was $8.8 \pm$ $0.69 \mathrm{~h}$ for animals expressing circadian rhythms $(n=7)$ and $5.57 \pm 1.27 \mathrm{~h}(n=4)$ for those expressing circatidal rhythms. The duration of activity for daily or circatidal

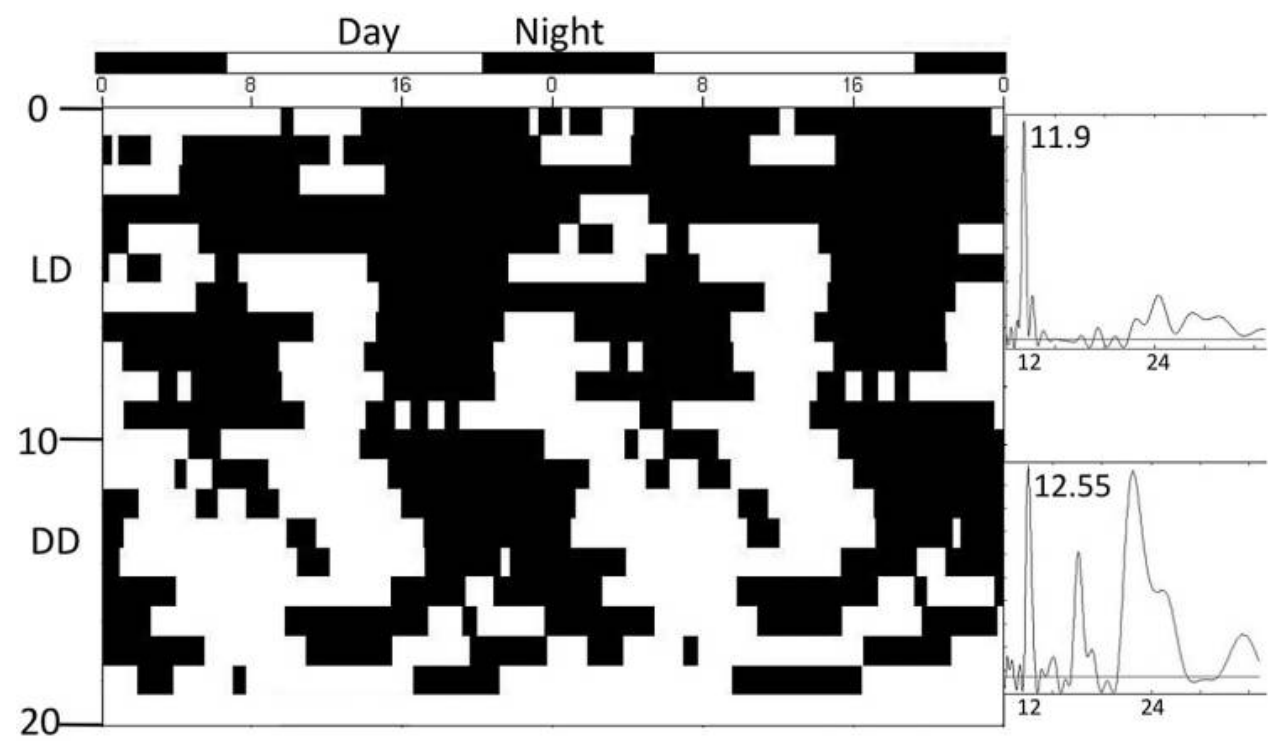

Figure 4. Locomotor activity recorded from a juvenile horseshoe crab expressing a circatidal pattern of activity in both LD and DD. The circatidal rhythm became more apparent when the animal was exposed to DD, indicating some masking of the activity pattern during LD. This is also why tau increased from 11.9 to 12.55 . See Fig. 1 for a full description of figure components. 
patterns of activity was not significantly different between LD and DD conditions.

\section{Discussion}

This is the first study to document clear circatidal activity rhythms in juvenile American horseshoe crabs. While only $20 \%$ of the animals expressed a circatidal rhythm when exposed to a light/dark cycle (LD) (Fig. 4), about half of them expressed a circatidal rhythm when in constant darkness (DD) (Figs. 2, 3, 4). Furthermore, many of the animals that expressed daily activity patterns in LD also exhibited subtle indications of a circatidal rhythm (Fig. 3), which can also be seen in the previous studies by Casterlin and Reynolds (1979) and Borst and Barlow (2002). With the benefit of hindsight, it is possible that, with an extended time in DD, the secondary peak of activity reported in these previous studies would have become more prevalent, yielding a more obvious circatidal rhythm.

The activity patterns seen in the juveniles tested in this study are similar to previous results with adult horseshoe crabs. When adults are exposed to an LD cycle, different individuals express different types of rhythms: some express tidal rhythms, others express daily rhythms, and still others a mixture of the two (Chabot et al., 2008; Chabot and Watson, 2010). Moreover, when they are subsequently exposed to DD, they also tend to switch to a tidal pattern of activity (Chabot et al., 2004, 2008; Watson et al., 2008; reviewed in Chabot and Watson, 2010). These patterns of activity could be the result of two different mechanisms, both of which are described in the following paragraphs.

Although all life-history stages of horseshoe crabs express some type of daily activity pattern, it is not known if this is the result of an endogenous circadian clock or a phenomenon called "masking." Masking occurs when exogenous cues, such as light, influence the expression of a behavior, such as locomotion, in a manner that make it appear as if the behavior has a particular type of rhythm, or pattern. In this study, 15 of 24 animals expressed a daily pattern of activity in LD (Figs. 1, 2, 3). It is well documented that adult horseshoe crabs possess an endogenous circadian clock that controls the sensitivity of their eyes (Barlow et al., 1980; Barlow, 1983; Barlow and Powers, 2003), but recent studies indicate that this particular clock does not appear to influence locomotion (Watson et al., 2008). An alternative explanation for the data presented is that patterns of locomotion expressed by juvenile and adult horseshoe crabs are the result of the interplay between an endogenous clock, which controls circatidal rhythms, and the masking influences of light and dark. For example, in some cases (Fig. 2), the nocturnal bout of activity expressed by animals in LD continued in DD, and then a second bout of activity emerged in DD during the subjective day. This second peak, apparently under the control of a clock con- trolling circatidal rhythms, may have been suppressed by light during the LD cycle. Masking of a circatidal activity pattern by a light cycle is not unusual; it has been shown in at least three organisms in addition to adult horseshoe crabs: Uca spp., Carcius maenas, and Sesarma reticulatum (Naylor, 1958; Honegger, 1973; Palmer, 1990; Chabot et al., 2008). We have also documented this preference for activity during only one of the two high tides in a given day in freely behaving adult horseshoe crabs in their natural habitat. One particular animal clearly preferred to be active only during the high tide that took place in the day (Watson, unpubl. data). Therefore, while our data appear to provide evidence of a circadian clock influencing locomotion in juvenile horseshoe crabs, it is perhaps more likely that the patterns observed are the result of the influence of LD cycles on an underlying tendency to express a tidal rhythm of locomotion.

Whereas the molecular mechanisms underlying circadian clocks are well established (Dunlap, 1999), it remains to be determined how rhythms of about $12.4 \mathrm{~h}$ are created within the nervous system of many intertidal organisms. Our working hypothesis is that the circatidal activity rhythm in horseshoe crabs is created by combining two circalunidian clocks that are 180 degrees out of phase, with each clock controlling one of the two bouts of tidal activity that occur each day. This is the essence of the circalunidian hypothesis proposed by Palmer (1990, 1995a), and it would not require the evolution of a new network of molecular interactions capable of producing a rhythm of about $12.4 \mathrm{~h}$ versus one of about $24 \mathrm{~h}$. Instead, two separate clocks of about $24 \mathrm{~h}$ could be used, which is how fruit flies control their two daily bouts of activity at dawn and dusk (Taghert and Shafer, 2006). Of the four possible indicators of a circalunidian clock, the juveniles in this study exhibited three: (1) two rhythms with different periodicities; (2) "splitting" of one activity bout into two; and (3) activity bouts of different durations. The variety of activity patterns expressed by the animals in this study is not unusual for intertidal organisms. Three species of crabs (Carcinus maenas, Emerita talpoida, and Uca spp.) also exhibit a wide variety of patterns, including tidal, daily, a combination of both, and arrhythmic (Bennett et al., 1957; Barnwell, 1966). In addition, adult horseshoe crabs express a range of activity patterns, both in the laboratory and in their natural habitat (Chabot and Watson, 2010). This variability is evident even when only males of the same size, collected at the same location, are used. Furthermore, horseshoe crabs have a terminal molt, so molt stage is unlikely to be a factor influencing the type of behavioral rhythms that we have documented in adult animals. While molt stage could influence the results of this experiment, no horseshoe crabs molted during their trial or for the 2 weeks afterward, reducing the probability that molt stage was a factor. Therefore, it appears that horseshoe crabs, and probably many other marine intertidal animals, possess endogenous clocks 
that help them to anticipate environmental cycles and give them the ability to sense environmental inputs and use the appropriate inputs to synchronize their activities to the ambient conditions in their local environment.

\section{Acknowledgments}

We are very grateful to Dr. Daniel Gibson (Worcester Polytechnic Institute) for helping us find and collect juvenile horseshoe crabs on Cape Cod, Massachusetts. He also provided many excellent suggestions that helped our study. We also thank Jason Goldstein, Tom Langley, and Tracy Pugh for helpful discussions and assistance with the experimental design and data analyses. Finally, we are grateful for the help of many undergraduates with aspects of the project, including Haley White, Suzanne Johnson, Suzanne LaChance, Alysia Campbell, Michael Lemmen, Mallory Chaput, and Kyle Jenks. This research was supported by UNH Graduate School grants to ED and NSF grant (NSF-IOS 090342) to CCC and WHW III.

\section{Literature Cited}

Aschoff, J. 1960. Exogenous and endogenous components in circadian rhythms. Cold Spring Harb. Svmp. Ouant. Biol. 25: 11-28.

Barlow, R. B., Jr. 1983. Circadian rhythms in the Limulus visual system. J. Neurobiol. 3: 856-870.

Barlow, R. B., and M. K. Powers. 2003. Seeing at night and finding mates: the role of vision. Pp. 83-102 in The American Horseshoe Crab, C. N. Shuster, Jr., R. B. Barlow, Jr., and H. J. Brockmann, eds. Harvard University Press, Cambridge, MA.

Barlow, R. B., Jr., S. C. Chamberlain, and J. Z. Levinson. 1980. Limulus brain modulates the structure and function of the lateral eyes. Science 210: 1037-1039.

Barnwell, F. H. 1966. Daily and tidal patterns of activity in individual fiddler crab (genus $U c a$ ) from the Woods Hole region. Biol. Bull. 130: $1-17$.

Battelle, B. A. 2006. The eyes of Limulus polyphemus (Xiphosura, Chelicerata) and their afferent and efferent projections. Arthropod Struct. Dev. 35: 261-274.

Bennett, M. F., J. Shriner, and R. A. Brown. 1957. Persistent tidal cycles of spontaneous motor activity in the fiddler crab, Uca pugnax. Biol. Bull. 112: 267-275.

Borst, D., and R. B. Barlow. 2002. Circadian rhythms in locomotor activity of juvenile horseshoe crabs. Biol. Bull. 203: 227-228.

Casterlin, M. E., and W. W. Reynolds. 1979. Diel locomotor-activity pattern of juvenile Limulus polyphemus (Linnaeus). Rev. Can. Biol. Exp. 38: 43-44.

Chabot, C. C., and W. H. Watson. 2010. Circatidal rhythms of locomotion in the American horseshoe crab Limulus polyphemus: underlying mechanisms and cues that influence them. Curr. Zool. 56: 499517.

Chabot, C. C., J. Kent, and W. H. Watson III. 2004. Circatidal and circadian rhythms of locomotion in Limulus polyphemus. Biol. Bull. 207: 72-75.

Chabot, C. C., S. H. Betournay, N. R. Braley, and W. H. Watson. 2007. Endogenous rhythms of locomotion in the American horseshoe crab, Limulus polyphemus. J. Exp. Mar. Biol. Ecol. 345: 79-89.
Chabot, C. C., S. J. Skinner, and W. H. Watson III. 2008. Rhythms of locomotion expressed by Limulus polyphemus, the American horseshoe crab: I. Synchronization by artificial tides. Biol. Bull. 215: 34-45.

Chabot, C. C., J. F. Yelle, C. B. O'Donnell, and W. H. Watson III. 2011. The effects of water pressure, temperature, and current cycles on circatidal rhythms expressed by the American horseshoe crab, Limulus polyphemus. Mar. Freshw. Behav. Physiol. 44: 43-60.

Chapman, R. M., and A. B. Lall. 1967. Electroretinogram characteristics and the spectral mechanisms of the median ocellus and the lateral eye in Limulus polyphemus. J. Gen. Phvsiol. 50: 2267-2287.

Chiu, H. M. C., and B. Morton. 2004. The behaviour of juvenile horseshoe crabs, Tachypleus tridentatus (Xiphosura), on a nursery beach at Shui Hau Wan, Hong Kong. Hydrobiologia 523: 29-35.

Dunlap, J. C. 1999. Molecular bases for circadian clocks. Cell 96: 271-290.

Ehlinger, G. S., and R. A. Tankersley. 2006. Endogenous rhythms and entrainment cues of larval activity in the horseshoe crab Limulus polyphemus. J. Exp. Mar. Biol. Ecol. 337: 205-214.

Errigo, M., C. McGuiness, S. Meadors, B. Mittmann, F. Dodge, and R. Barlow. 2001. Visually guided behavior of juvenile horseshoe crabs. Biol. Bull. 201: 271 - 272.

Forward, R. B., Jr., H. Diaz, and J. H. Cohen. 2005. The tidal rhythm in activity of the mole crab Emerita talpoida. J. Mar. Biol. Assoc. UK 85: 895-901.

Graham, C. H., and H. K. Hartline. 1935. The response of single visual sense cells to lights of different wave lengths. J. Gen. Phvsiol. 18: 917-931.

Honegger, H. W. 1973. Rhythmic motor activity responses of the California fiddler crab Uca crenulata to artificial light conditions. Mar. Biol. 18: 19-31.

Meadors, S., C. McGuiness, F. A. Dodge, and R. B. Barlow. 2001. Growth, visual field, and resolution in the juvenile Limulus lateral eye. Biol. Bull. 201: 272-274.

Meury, T. W., and D. G. Gibson. 1990. Force generation in juvenile Limulus polyphemus: effect on mobility in the intertidal environment. Bull. Mar. Sci. 47: 536-545.

Naylor, E. 1958. Tidal and diurnal rhythms of locomotory activity in Carcinus maenas (L.). J. Exp. Biol. 35: 602-610.

Palmer, J. D. 1990. The rhythmic lives of crabs. BioScience 40: 352358.

Palmer, J. D. 1995a. Review of the dual-clock control of tidal rhythms and the hypothesis that the same clock governs both circatidal and circadian rhythms. Chronobiol. Int. 12: 299-310.

Palmer, J. D. 1995b. The Biological Rhythms and Clocks of Intertidal Animals. Oxford University Press, New York.

Rudloe, A. 1979. Locomotor and light responses of larvae of the horseshoe crab, Limulus polyphemus (L.). Biol. Bull. 157: 494-505.

Rudloe, A. 1981. Aspects of the biology of juvenile horseshoe crabs, Limulus polyphemus. Bull. Mar. Sci. 31: 125-133.

Sekiguchi, K., H. Seshimo, and H. Sugita. 1988. Post-embryonic development of the horseshoe crab. Biol. Bull. 174: 337-345.

Shuster, C. N., Jr. 1982. A pictorial review of the natural history and ecology of the horseshoe crab Limulus polyphemus, with reference to other Limulidae. Pp. 1-52 in Physiology and Biology of Horseshoe Crabs: Studies on Normal and Environmentally Stressed Animals, J. Bonaventura, C. Bonaventura, and S. Tesh, eds. Alan R. Liss, New York.

Taghert, P. H., and O. T. Shafer. 2006. Mechanisms of clock output in the Drosophila circadian pacemaker system. J. Biol. Rhvthms 21: 445-457.

Watson, W. H., and C. C. Chabot. 2010. High resolution tracking of adult horseshoe crabs Limulus polyphemus in a New Hampshire estuary using fixed array ultrasonic telemetry. Curr. Zool. 56: 599-610.

Watson, W. H. III, L. Bedford, and C. C. Chabot. 2008. Rhythms of 
locomotion expressed by Limulus polyphemus, the American horseshoe crab: II. Relationship to circadian rhythms of visual sensitivity. Biol. Bull. 215: 46-56.

Watson, W. H., S. Y. Schaller, and C. C. Chabot. 2009. The relationship between small- and large-scale movements of horseshoe crabs in the great bay estuary and Limulus behavior in the laboratory.
Pp. 131-147 in Biology and Conservation of Horseshoe Crabs, J. T. Tanacredi, M. L. Botton, and D. R. Smith, eds. Springer, New York.

Wyse, G. A., and N. K. Dwyer. 1973. The neuromuscular basis of coxal feeding and locomotory movements in Limulus. Biol. Bull. 144: 567579. 